animals and in man and $I$ am surprised that anyone should suppose I think otherwise. This erroneous suggestion must, I suppose, have owed its origin to my expressed belief that the disease is sometimes generable apart from contagion, coupled with the widely spread notion that a contagious disease cannot arise $d e$ novo, the latter being a conclusion which to many seems to have been made certain by the discovery that micro-organisms constitute the contagia of so many of the communicable diseases.

Granting the facts of contagion, let us look for a moment at the possible modes of origin of a contagious disease. One or other of three views may be held concerning the origin of the contagium. We may, to put it briefly, believe (1) in special creation ; (2) in transmutation ; and (3) in its de novo origin.

1. We have in the first place the notion that the various contagia have been specially created with a view to the production of this or that disease. This surely cannot be regarded as a scientific hypothesis. It is a teleolngical conception entirely out of harmony with existing beliefs. And if it is to be rejected a de novo origin, either in present or in past times, by one or other of the two remaining modes of origin is alone open for our acceptance. It is well that this should be fully realised.

2. The second view implies that there is no absolute demarcation between non-pathcgenic and pathogenic organisms, and in its favour there is an immense amount of evidence showing the mutability, both in form and in function, of the micro-organisms in question. Some who do not adequately appreciate the weight of this evidence are, as a distinguished physician has lately said, willing to subscribe to the view that "the origin of the germs of disease was probably in the remote geological past," even though as to all the conditions of such occurrences they must be absolutely devoid of all knowledge. This is a nebulous and unsubstantiated point of view which does not appeal to me. I prefer to seek for actual evidence of the occurrence of such transformations in the present day, and for this reason, in your issue of Oct. 31st, p. 12:20, I called attention to the conditions of origin of two experimentally produced forms of septicæmia and contended that a fair and impartial consideration of the evidence (apart from unproved assumptions) should lead to the belief that both "Davaine's septicæmia" and "Pasteur's septicæmia" had been produced over and over again de novo, and that the micro-organisms by which they are characterised (if not arising independently) must in such cases have been produced by the transformation of common organisms. In the case of " Davaine's septicæmia " the disease has been causéd by the injection of two or three drops of putrid blood taken from a previously healthy animal. Such blood soon swarms with organisms of different kinds The deadly specific germ could not have been contained in the healthy animal from which the blood was taken, and the specific bacillus ultimately produced in the putrefying blood is said never to have been recognised in the outside world apart from such blood. To assume, nevertheless, that this specific germ is omnipresent in the atmosphere and ever ready to drop into the blood with which experiment is about to be made seems to me an absurdly gratuitous and unfounded supposition. All the evidence points rather to the conclusion that the specific bacillus has been produced from one of the common forms at some particular stage in the putrefactive process. Again, in regard to "Pasteur's septicæmia," the fact that this disease can be produced in a previously healthy animal within 24 hours by the injection of a germ-free chemical irritant in to its peritoneal cavity cannot, I think, be satisfactorily explained by supposing that the organism which is the cause of the disease is always present in the intestine, and that the setting up of an intense inflammation in the peritoneum leads it to multiply rapidly and at once to begin to make its way through all the coats of the intestine in order to get into the peritoneal fluids. These are assumptions devoid of proof, and if $\mathrm{Dr}$. Fortescue-Brickdale is disposed to give them credence it seems a pity he should not have recollected that some of the same germ-free chemical irritant introduced into the subcutaneous tissue of the healthy animal under conditions, as Sir J. Burdon Sanderson said, "which preclude the possibility of the introduction of any infecting matter from without," will nevertheless give rise to the same contagious disease. Do the organisms which characterise it exist also in the subcutaneous tissues of healthy animals or does he suppose them to be so abundant in the air that they are always ready to baffle the most skilful experimenter whenever an opening is once made in the skin, however minute this may be ? It is, moreover, an absolute error for Dr. FortescueBrickdale to say that I regard the bacilli characterising Davaine's and Pasteur's septicæmia respectively as " altered forms of the same organism." No such view has been put forward by me. He is further wrong in supposing that 1 relied upon these experimental researches as furnishing a proof of the de novo origin of bacilli. I cited them rather as affording very strong evidence in favour of the transmutation hypothesis and as showing that some contagious diseases do arise de novo.

3 When I said in reference to micro-organisms I "have proved the possibility of their de novo origin" I was referring to the researches the results of which are recorded in the Annals and Magazine of Natural History for October last and to which reference was made in THE LANCET of Nov. 7th, p. 1316. I venture to think that the evidence there recorded, which will also be found in Section xxiii. of my "Studies in Heterogenesis" (to be published next week) is not capable of being explained in accordance with existing knowledge and commonly received views. The only legitimate interpretation of my observations and experiments, as I believe, is that bacteria and their allies can, and do, now arise by heterogene:is and the proof of this possibility I regard as of great importance for the science of medicine.

I am, Sirs, yours faithfully,

Manchester-square, Dec. 4th, $1903 . \quad$ H. Charlton Bastiar.

\section{THE ALIEN IMMIGRANT.}

To the Editors of THE LANCET.

SIRS, - I trust you will kindly give me an opportunity of replying in your columns to Mr. Morris Streimer's letter of Nov. 10 $\mathrm{th}^{1}$ and of thanking you at the same time for the very" valuable criticism of my book which appeared in THE LANCET of Nov. 7th (p. 1304) and which Mr. Streimer is pleased to describe as "partial." I have been absent in Paris or should have addressed you on the subject before.

Mr. Streimer objects to the assertion that the Jews are "a race apart" and says : "All experience and all study show that once social and legal restrictions are removed the people of any country tend to become homogeneous in their general characteristics." $\mathrm{He}$ ignores the fact that it is contrary to the precepts of the Hebrew faith that Israelites should intermarry with Gentiles and that therefore in their case no appreciable absorption among the surrounding populace takes place. They have kept themselves "a race apart" since, as before, their dispersion and are as much so in the United States to-day as anywhere else. I think that any impartial observer must admit that the national spirit among the Jews is increasing rather than diminishing. The great Zionist movement is based upon the national idea and though no trustworthy figures are available it is probable that several millions of Jews are Zionists. Why should Mr. Streimer take exception to the statement that the Jews are a race apart? For myself I can see nothing derogatory in it. Mr. Streimer ridicules my assertion that there are streets in the East-end where "it is an exception to hear the English language spoken." He ignores the official testimony, to which I refer, of Chief Superintendent Mulvaney of the " $\mathrm{H}$ " Division who told the Royal Commission on Alien Immigration that in six years 107 streets in Stepney alene had passed wholly into the occupation of aliens. It is not probable that the new inhabitants speak English.

I agree with Mr. Streimer when he lays stress on the question of sanitation. I notice that as recently as Nov. 23rd the medical officer of health of Stepney reported a case of small-pox-that of a Russian whose illness was notified two days after his arrival in England. And I observe that Mr. Cluer at Worship-street Police-court on Nov. 18th made the following remarks about some of our East-end immigrants : "You come into this country to make a living, defying or breaking our laws, crowding your dirt and indecency together, and bring your family after you." It is not, in my opinion, the case that "the question of our foreign population is but one aspect of the general social question." The question is whether we wish to have our own social ills aggravated by the constant arrival of aliens of this class who come here in consequence of no natural operation of the law 
of supply and demand but on account of governmental measures of extrusion adopted in Eastern Europe.

I am, Sirs, yours faithfully,

Chelsea Embankment, s.W.

W. EVANS. GORDON.

\section{THE URBAN HOSPITAL TREATMENT OF TUBERCULOSIS.}

To the Editors of THE LANOWT.

SIRS, - The report on the urban hospital treatment of tuberculosis by the committee appointed by the Society for the Study of Disease in Children to inquire into the matter and report to them is still under consideration by that body, and its publication in THE LANCET of Dec. 5th, p. 1590, was owing to an unfortunate oversight. As this report is still sub judioe its discussion at the present moment would be premature. - I am, Sirs, yours faithfully,

George Carpenter,

Welbeck-street, Cavendish-square, W., Dec. 7th, 1903.

\section{THE MORTALITY AFTER OPERATIONS FOR STRANGULATED UMBILICAL HERNIA.}

To the Editors of THE LANCET.

SIRS, - I shall be glad if any of your readers can give me a reference to any statistics with regard to this subject. I have been unable to find any definite information but that it is unexpectedly high I believe.

Hove, Dec. 3rd, 1903.

I am, Sirs, yours faithfully, ARTHUR H. BUCK.

\section{THE PHOSPHATES AND UREA OF URINE.}

\section{To the Editors of THE LANCET.}

SIRS,-I shall be obliged if you will give me space for a somewhat belated acknowledgment of the communications from Dr. H. Harper, Dr. A. W. Gilchrist, and others, in THE LANCET of the latter end of 1902, and January of this year, referring to a paper of mine on the above subject. ${ }^{1}$ These letters appeared at a period when serious illness prevented me from attending to anything, and I have only recently found an opportunity of looking through the back numbers of your journal.

To remove misconception (for I think there was some, partly owing perhaps to the results of the analyses having been tabulated, for the sake of brevity, so that the figures yielded by very different pathological samples were in juxtaposition), I should like to state, chiefly in reply to Dr. Gilchrist :1. That I never thought to "establish an analogy" between the diseases. In one not a medical man $I$ should think this presumptuous 2. As a scientific chemist I have long known the desirability that analyses of urine should represent the collective fluid excreted during 24 hours. But for the analyst and if $\mathrm{I}$ mistake not, for the medical man also, this is very often impracticable. The former, at all events, has to work with just what is submitted to him, frequently by the medical adviser, who cannot help himself. 3. Professing to no knowledge of medicine, I certainly did not intend it to appear as if I had had the temerity to make any precise comparison of the composition of tuberculous urine with that of the fluid from glycosuria or with other samples of urine from similar cases. No data were at my command for this sort of comparison, which was left, of course, to medical men. I sent these analyses, such as they were, to THE LANCET on the chance that they might be of some service or interest to my medical brethren; but I was far from wishing to seem to attach to them undue importance and was particular in giving what information I possessed, as to times, \&c., so as to show clearly that the samples were not representative of the entire 24 hours' excretion. Any remarks - they could hardly be called conclusions-were extremely guarded, and confined to comparisons of the most general kind, not with analyses of other pathological urines, but with such statements regarding the limits of composition of normal urine as are to be found in ordinary works of reference-by Halliburton, Hammarsten, Allen, Pearmain and Moor, and others; and referred only to the actual samples, as they were received. I do not at al claim infallibility for the remarks in question. At the worst, if the paper had no other use, the figures recorded such analytical results as may be yielded in particular circumstances and by limited samples, representing only part of the 24 hours - such as medical practitioners must often be forced to be content with. 4. As far as my own imperfect opportunities permitted me to judge, I was under the impression that there were not very many readily accessible analyses, at all events as full as that of the tuberculous sample, and personally I had never seen any published analysis of urine from a case of tuberole of the bladder. For my own information. I should be grateful for references to such analyses, and interested to know whether the figures are simular to, or different from, those yielded in other cases of tuberculosis, as of the lungs; also whether the "graph" in Dr. Gilchrist's communication represented the results from one sample of tuberculous urine or the mean of several.

Lastly, the cautiously chosen title of the paper, "Observed Variations," \&c.. was changed in the later communications to "The Low Phosphates and Urea," \&c. I must disclaim responsibility for this. My own use (in the paper) of the expression, "low phosphates" related solely to the particular set of analyses and to the actual specimens of urine received, imperfectly representative as they may have been. This was without any universal application or generalisation, such as the latter title might imply: I intended none.-I am, Sirs, yours faithfully,

EDWy G Clayton, F.I.C., F.C.S.

Holborn Viaduct, E.C., Nov. 30th, 1903.

\section{RADIUM AND THE BACILLUS TYPHOSUS. To the Edutors of THE LANCET.}

SIRS,- The following experiences with bromide of radium upon cultures of the bacillus typhosus may be of interest to some of your readers. The cultures were of the usual kind, in agar, and were exposed to the rays of 50 milligrammes of the salt for periods varying from 15 minutes to 48 hours. The longer exposures were in the dark in order to eliminate any inhibitory effect of daylight upon the cultures. The tubes containing the cultures were at first placed horizontally above the radium at a distance of five centimetres but were afterwards allowed to rest in an upright position actually upon the mica cover of the box containing the radium, so that the culture received the full rays diverying from below upwards throughout its length. From each tube subcultures were afterwards taken without difficulty and so far as could be observed there seemed to be no inhibitory action upon the growth of the culture. Rather the contrary, for, in the opinion of more than one observer, examining the cultures under a high power, there seemed to be more activity in those cultures which had been subjected to the longer exposures, and in cultures which had been exposed, than in others of the same date which had not been exposed to the radium but had been simply excluded from daylight.

These experiences would seem to lead one in the direction of supposing the beneficial action of radium in certain cases to be that of stimulation of normal tissue rather than directly bactericidal. It is not easy to determine accurately the activity of a radium salt, but at a rough estimate the radium used in this instance is sufficiently strong to make its rays apparent upon the screen through a thickness of 15 coins, half-crowns and pennies. They pass easily therefore through the thickest part of a Cabaud gauge and in therapeutic use an application to the skin of five minutes produces redness and one of ten minutes a slight burn, appearing after two days. The cultures were kindly prepared for me in the laboratory of the Westminster Hospital.

I am, Sirs, yours faithfully,

Beaumont-street, W., Dec. 5th, $1903 . \quad$ R. BROWNE-CARTHEW.

\section{ST. JOHN'S HOUSE OF REST, MENTONE.} To the Editors of THE LANOET.

SIRS, - We are anxious through the medium of your journal to draw the attention of the members of the medical profession to the existence in Mentone of St. John's House of Rest which we believe to be little known to them. The institution, which was founded 25 years ago, is intendedifor 